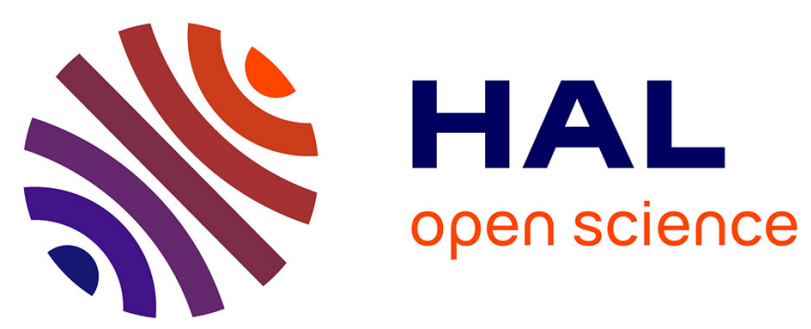

\title{
Proposition of Eco-feature: a new CAD/PLM data model for an LCA tool
}

\author{
Raoudha Gaha, Abdelmajid Benamara, Bernard Yannou
}

\section{To cite this version:}

Raoudha Gaha, Abdelmajid Benamara, Bernard Yannou. Proposition of Eco-feature: a new CAD/PLM data model for an LCA tool. CMSM 2017: The Seventh International Congress Design and Modelling of Mechanical Systems, Mar 2017, Hammamet, Tunisia. 10.1007/978-3-319-66697-6_74 . hal-01673543

\section{HAL Id: hal-01673543 https://hal.science/hal-01673543}

Submitted on 30 Dec 2017

HAL is a multi-disciplinary open access archive for the deposit and dissemination of scientific research documents, whether they are published or not. The documents may come from teaching and research institutions in France or abroad, or from public or private research centers.
L'archive ouverte pluridisciplinaire HAL, est destinée au dépôt et à la diffusion de documents scientifiques de niveau recherche, publiés ou non, émanant des établissements d'enseignement et de recherche français ou étrangers, des laboratoires publics ou privés. 


\title{
Proposition of Eco-feature: a new CAD/PLM data model for an LCA tool
}

\author{
Raoudha GAHA ${ }^{1}$, Abdelmajid BENAMARA ${ }^{1}$, Bernard YANNOU ${ }^{2}$ \\ ${ }^{1}$ Ecole Nationale d'Ingénieurs de Monastir, Laboratoire de Génie Mécanique, Tunisie \\ raoudha.gaha@gmail.com \\ abdel.benamara@enim.rnu.tn \\ ${ }^{2}$ Ecole Centrale de Paris, Laboratoire de Génie Industriel, France \\ bernard.yannou@centralesupelec.fr
}

\begin{abstract}
Today, the environmental problems become serious and they are highlighted in regulations frameworks. Then, the use of Life cycle assessment (LCA) tools, for assessing products environmental impacts, is necessary, till Computer Aided Design (CAD) phase, for manufactures aiming at guarding their market places. Required LCA data (processes) can be provided from $\mathrm{CAD}$ and Product Life Management integrated systems (CAD/PLM), which became a necessity for industries to manage easily their data. In this paper, we propose a new CAD data model oriented ecodesign which we name "Ecofeature", based on the exploration of CAD/LCA systems to extract possible features life cycle scenarios, in order to select the most ecological one. Hence, firstly, we present the state of the art of researches aiming at connecting CAD/PLM systems to LCA tools. Secondly we present our new approach and describe its advantages. Finally, we present a case study to valid the new proposed concept.
\end{abstract}

Keywords: CAD, PLM, ecodesign, Eco-feature, scenarios.

\section{Introduction}

Design stage is very critical as many decisions impacting the downstream development activities, the product cost and environmental impact are made in this stage. Today, energy, resources and environmental problems become more and more serious. That's why they are highlighted in regulations frameworks such as WEEE (European Union,, 2003). 
Over the years, numerous "Design for environment (Dfe)" concepts/methods and tools have been developed in order to increase the environmental conscious efficiency at the design stage, and reduce the total impact of the product (Leibrecht, 2005), (Capelli 2006),(Mathieux et al., 2005), (Mathieux and Roucoules, 2007) (Morbidoni, 2012), etc. These researches highlight the necessity of the Life Cycle Modelling (LCM) for the environmental assessment. PLM systems are the source of required LCA data in mostly developed works.

In this paper we present firstly the state of the art of connecting CAD/PLM systems to an environmental assessment tool. Secondly, based on these connections, we propose the based-scenarios concept of eco-feature. Finally we present a case study to valid the proposed model.

\section{Analysis of connecting CAD/PLM systems to LCA tools}

\subsection{Product Life Management systems (PLM)}

Product lifecycle management is a comprehensive information system that coordinates all aspects of a product from initial concept to its eventual retirement. It contains data about different stages of a product development process; analysis and design stages, manufacturing, product launch, distribution, quality assurance, in-service maintenance and spare parts provisions. It supports the management of a portfolio of products, processes and services from initial concept, through design, launch, production and use to final disposal. They co-ordinate products, project and process information throughout new product introduction, production, service and retirement among the various actors who must collaborate to bring the concept to finish product.

\subsection{Eco-designing with CAD/PLM: State of the art}

For assessing environmentally a CAD model, a Life Cycle Assessment (LCA) tool requires Life Cycle Data (LCD) (from cradle to grave). However, CAD systems can only offer geometric data which is insufficient. Then, the use of PLM systems, which supplies necessary data for an LCA especially about processes, is present in most researches aiming at eco-designing in CAD phase. Among these works we find (Mathieux and Roucoules 2007), (Segonds et al. 2011), (Rio et al. 2013) and (Rio, 2012).

In the literature realized in our previous work (Gaha et al. 2013), we have identified that the extracted data from CAD/PLM systems and required by an LCA tool are provided from features; such as the "DEMONSTRATOR" developed by (Mathieux et al. 2005). This prototype tool binds CATIA(a CAD software) and EIME (an LCA software). CATIA is connected to a Product Life Management (PLM) system that extracts all data provided by different used features. The established system then selects necessary LCA 
data and transfers them to EIME to calculate and show the environmental impact. Also, (Jain, 2009) use the integration between PLM and CAD presents a plugin (Eco-fit) designed for 3DSmax using the Eco-indicator99 (EI99), an eco-assessment methodology and database designed to evaluate CAD-based products. There is also "EcoCAD" presented by (Cappelli et al. 2007), which is based on the analysis of the tree structure of a CAD project composed of assemblies, subassemblies, parts, and features. The lake of these works is that only one scenario is environmentally evaluated. Computer aided sustainable tool "CAST Tool" presented by (Morbidoni et al. 2011) provide a prototype with an open access database, allowing products to be evaluated regardless of the CAD or LCA systems used. Benefits are essentially due to selecting more than one production process, introducing lifecycle scenarios and extracting the right amount of geometrical and non geometrical data from the CAD data structure and PLM databases. "CAST Tool" overcomes many weaknesses such as the single scenario introduced where the evaluation of different possible scenarios is available. However, the evaluation is post modelling that is realized on a final part where modifications are difficult to implement, especially when it is a complex part. This explains the need for a real time evaluation tool.

From the overview of last works presented for connecting CAD/PLM systems to an LCA tool, we generated four major gaps; first, it was noted that the majority of the tools and methodologies presented, realize environmental assessments to a final part (postmodeling assessment), hence, modifications become a hard task to the designer when it is the case of a complex part. Second, the objective of these works was essentially the extraction of necessary data relative to a single Life Cycle (LC) scenario of the final part; where CAD/PLM systems are able to provide more LC scenarios for the part. Finally, works using this integration are interested only in the manufacturing phase, although products can be impacting in other phase such as use or end of life (EOL). This led us to propose a real time data model that can overcome these gaps. The approach proposed can provide Environmental Evaluation (EE) till features attribution. It is based on scenarios provided by CAD/PLM integration.

\section{Approach for eco-designing in CAD phase based on PLM systems}

The approach proposed can provide Environmental evaluation (EE) till features attribution. It is based on scenarios provided by CAD and PLM (Product Life Management) integration. CAD/PLM systems can provide information about different LC processes because PLM systems can include the requirements phase, analysis and design stages, manufacturing, product launch, distribution, quality assurance, in service maintenance and spare parts provisions).As deduced previously, CAD feature is the source of data. Hence, we propose to extract its related data till its attribution from CAD/PLM system as shown in table 1. 
Table 1. CAD feature data from CAD/PLM system.

\begin{tabular}{ll}
\hline Information systems & Related DATA \\
\hline CAD & Forms \\
& Dimensions \\
& Materials \\
& Volumes \\
& Production Process \\
PLM & Materials \\
& Choice of « make or buy » \\
& Thermal or surface treatments \\
\hline
\end{tabular}

CAD/PLM can offer different types of data which can be used to generate possible LC scenarios. These scenarios can include necessary LCA data and then environmentally evaluated, in order to choose the most ecological one till feature's selection as mentioned in figure 1. The environmental impact is calculated with Eco-Indicator method and shown to the designer as End-Points Indicators (Resources, Human Health, Eco-system damages).

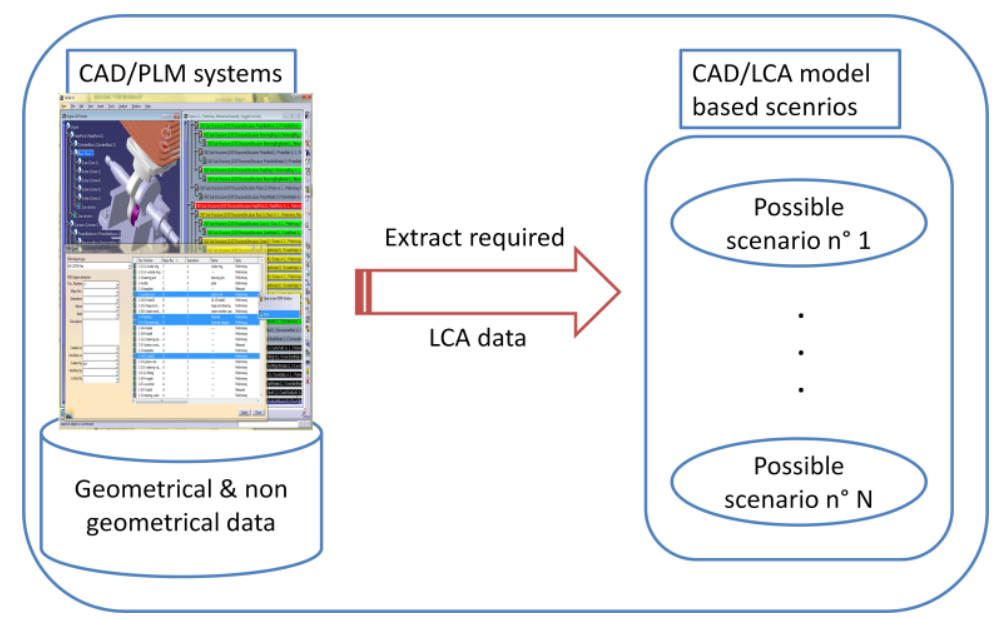

Fig. 1 Proposed CAD/LCA based scenarios model extracted from CAD/PLM systems

A CAD feature can involve different machining scenarios with different parameters such as selecting machine tool, cutting tool, energy consumption, etc. It may also carry other types of data when it is developed in an integrated CAD/ PLM (Gaha et al 2014). Provided data will allow assessing all scenarios proposed in order to select the most ecological one. Proposed alternative scenarios can be shown with their Environmental Impact (EI) simply.

Enriching a classic CAD feature with LCA data led us to propose the concept of "Ecofeature", which is a classic CAD feature that can be environmentally assessed. It is a new CAD data model oriented eco-design. An UML of the Eco-feature is presented in figure 2, 
which shows that Eco-feature is a special type of feature that we have assigned processes such as material production, transport and landfill. The way, how to generate these entities from a CAD model is described in (Gaha, 2014). In the next section we present a case study to valid this proposed concept.

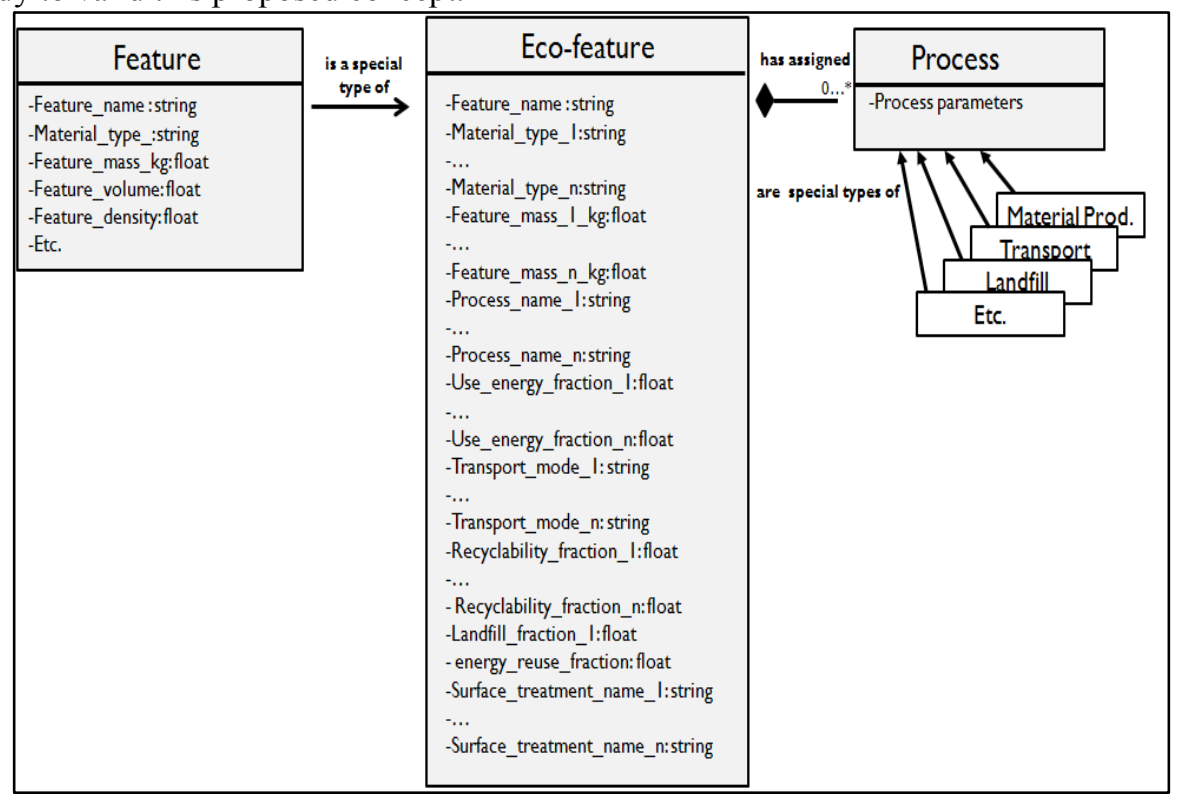

Fig. 2 The UML of Eco-feature

\section{Validation of the proposed concept on a case study}

From the study realized in our previous work (Gaha et al. 2104 a) we consider the basin mixer as a case study. The environmental assessment shows that the use phase is the most impacting stage in the life cycle of the product. The related CAD feature to this stage is the hole of water injection (Figure 3). By applying the concept of Eco-feature to this classic feature (the hole) we obtain different possible scenarios, each one has different environmental evaluation result from the other.

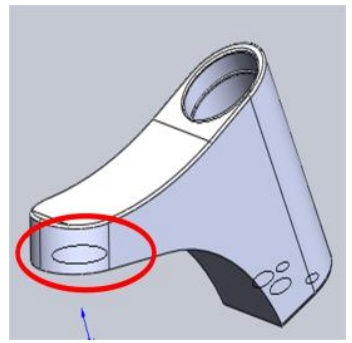

Fig. 3 The feature hole case study of the basin mixer 
To generate the Eco-feature we consider 2 scenarios, where raw material (RM), use (U) and transport $(\mathrm{T})$ phases are in relation and 3 scenarios for manufacturing $(\mathrm{M})$ and end of life (EoL) phases. These scenarios are presented in table 2 and table 3.

Table 2 Hole data related to material, use and transport phases

\begin{tabular}{lllll}
\hline Phase & Scenario 1 & \multicolumn{3}{c}{ Scenario 2} \\
\hline Raw material & Material : Brass & Weight: $0.025 \mathrm{~kg}$ & Material : Brass & Weight : $0.0125 \mathrm{~kg}$ \\
\hline Transport & Mean :truck $<16 \mathrm{t}$ & Weight : 0.025 & Mean :truck $<16 \mathrm{t}$ & Weight : 0.0125 \\
\hline Use & Water : $36000 \mathrm{~kg}$ & & Water : $54000 \mathrm{~kg}$ & \\
\hline
\end{tabular}

Table 3. Hole data related to manufacturing and end of life phases

\begin{tabular}{|c|c|c|c|c|c|c|}
\hline Phase & Scenario 1 & & Scenario 2 & & Scenario 3 & \\
\hline \multirow[t]{4}{*}{ Manufacturing } & Process : & Drilling & Process : & Turning & Process : & $\begin{array}{l}\text { Drilling } \\
\mathrm{NC}\end{array}$ \\
\hline & Temps : & $4 \mathrm{mn} 20$ & Time : & $4 \mathrm{mn} 15$ & Time : & $3 \mathrm{mn} 50$ \\
\hline & Energy: & $\begin{array}{l}0,0045 \\
\text { Kw }\end{array}$ & Energy: & $\begin{array}{c}0,0055 \\
\mathrm{Kw}\end{array}$ & Energy: & $0,005 \mathrm{Kw}$ \\
\hline & $\begin{array}{l}\% \text { waste re- } \\
\text { covery: }\end{array}$ & $50 \%$ & $\begin{array}{l}\% \text { waste re- } \\
\text { covery: }\end{array}$ & $60 \%$ & $\begin{array}{l}\% \text { waste re- } \\
\text { covery }\end{array}$ & $80 \%$ \\
\hline End of life & $\begin{array}{l}\% \text { waste recy- } \\
\text { cling }\end{array}$ & $50 \%$ & $\begin{array}{l}\% \text { waste recy- } \\
\text { cling }\end{array}$ & $60 \%$ & $\begin{array}{l}\% \text { waste re- } \\
\text { cycling }\end{array}$ & $80 \%$ \\
\hline
\end{tabular}

We obtain then 6 life cycle possible scenarios for the Eco-hole, which are presented in figure 4. The LCA tool "Bilan Produit" (Ademe, 2008) gives the result of comparison of their environmental evaluation in Figure 5 .

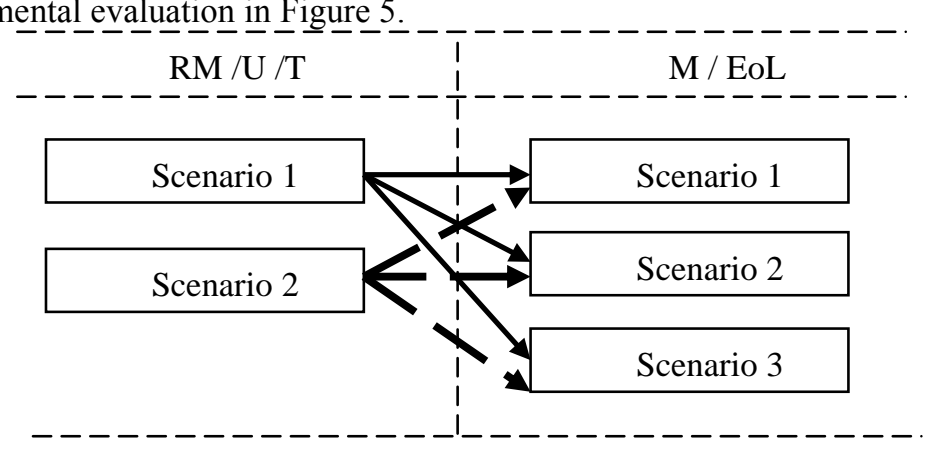

Fig. 4 Possible life cycle scenarios of the hole case study of the basin mixer 


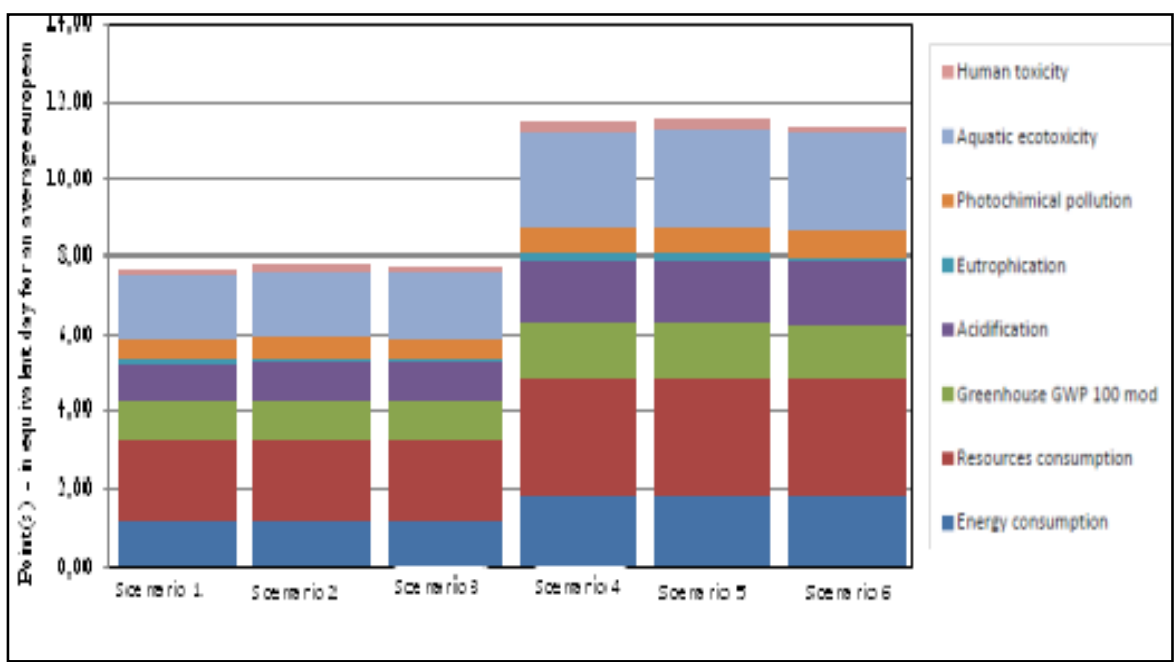

Fig. 5 Comparison of the environmental impacts of possible life cycle scenarios of the hole

\section{Conclusion}

This paper presents the eco-feature concept which is a LCA data model rxtracted from $\mathrm{CAD} / \mathrm{PLM}$ system. It is obtained from an enrichment Semantics of classical features of $\mathrm{CAD}$ systems by the three information Concerning the geometry, the material and the manufacturing process. A geometry-material-process combination of Manufacturing constitutes a life scenario for an eco-feature. Different scenarios can be generated for the same feature. The different scenarios are the inputs for an LCA tool. The result obtained guide $\mathrm{CAD}$ designer to choose the most ecological one. The approach proposed is applied to a feature of a basin mixer (hole) to valid its brings to ecodesign.

\section{References}

\section{Journal article}

Gaha, Raoudha, Benamara, Abdelmajid, et Yannou, Bernard. (2014). Eco-design of a basin mixer in geometric modeling phase. Key Engineering Materials, 2014, vol. 572, p. 7-11.

Leibrecht, S. (2005). Fundamental Principles for CAD based Ecological Assessments (9 pp). The International Journal of Life Cycle Assessment,10(6), 436-444.

Gaha, R., Yannou, B., \& Benamara, A. (2014). A new eco-design approach on CAD systems. International journal of precision engineering and manufacturing,15(7), 1443-1451. 
Segonds, F., N. Maranzana, P. Véron and A. Aoussat,(2011) "Collaborative Reverse Engineering Design Experiment Using PLM Solutions", International Journal of Engineering Education, vol. 27, no. 5, pp. $1037-1045,2011$.

Rio, M., T. Reyes and L. Roucoules, (2013) “Toward proactive (eco)design process: modeling information transformations among designers activities", Journal of Cleaner Production, vol. 39, pp. 105-116, 2013.

Journal article only by DOI

Capelli F., (2006) Integration of LCA and Eco-Design guideline in a virtual cad framework, The 13th edition of the CIRP International conference on Life Cycle Engineering, Leuven, 2006.

Cappelli, F., Citti, P., Delogu, M., and Pierini, M. (2007).Strumento informatico integrato in ambiente cad per l'analisi preventiva degli impatti ambientali dei processi/prodotti in fase di produzione. Atti del XXXVI Convegno Nazionale AIAS.

Morbidoni, A., Favi, C., and Germani, M. (2011) "CAD-Integrated LCA Tool: Comparison with dedicated LCA Software and Guidelines for the improvement". Glocalized Solutions for Sustainability in Manufacturing, 2001, 569-574.

Mathieux F. and L. Roucoules, (2007) "Connecting CAD and PLM systems with ecodesign software: Current experiences and future opportunities", International Conference on Engineering Design (ICED'07), 2007

Mathieux, F., Roucoules, L., Lescuyer, L., and Bouzidi, Y (2005).,“'Opportunities and Challenges for Connecting Environmental Assessment Tools and CAD Software," Proc. of LCM 2005-Innovation by Life Cycle Management, 2005.

Online document (no DOI available)

ADEME, Bilan Produit (2008) , http://www.ademe.fr/bilanproduit/ Manuel bilan produit (2008) /Eco-Invent, Swiss Centre For Life Cycle Inventories, 2009, http:// www.ademe.fr/bilanproduit.

European Union, (2003), Directive 2002/96/EC of the 27 January 2003 on waste electrical and electronic equipment (WEEE).

\section{Dissertation}

Jain, P. (2009) Design of an Interactive Eco-Assessment GUI tool for Computer Aided Product Design (Doctoral dissertation, Indian Institute of Technology) 2009.

Morbidoni, A. (2012). The ecodesign issue: proposal for a new approach, methodology and tools. Doctoral dissertation, Università Politecnica delle Marche (2012).

Rio. M, (2012) A l'interface de l'ingénierie et de l'ana lyse environnementale :fédération pour une écoconception proactive, thèse de doctorat à l'université technologique de Troyes, 2012.

Gaha. R, (2014), Eco-conception et CAO Paramétrique, Thèse de Doctorat à l'école nationale d'ingénieurs de Monastir, (2014). 